\title{
Charles Galton Darwin's 1922 quantum theory of optical dispersion
}

\author{
Benjamin Johnson ${ }^{1,2, \text { a }}$ \\ ${ }^{1}$ Max Planck Institute for the History of Science Boltzmannstraße 22, 14195 Berlin, \\ Germany \\ ${ }^{2}$ Fritz-Haber-Institut der Max-Planck-Gesellschaft Faradayweg 4, 14195 Berlin, \\ Germany
}

Received 13 October 2017 / Received in final form 4 February 2020

Published online 29 May 2020

(c) The Author(s) 2020. This article is published with open access at Springerlink.com

\begin{abstract}
The quantum theory of dispersion was an important conceptual advancement which led out of the crisis of the old quantum theory in the early 1920s and aided in the formulation of matrix mechanics in 1925. The theory of Charles Galton Darwin, often cited only for its reliance on the statistical conservation of energy, was a wave-based attempt to explain dispersion phenomena at a time between the theories of Ladenburg and Kramers. It contributed to future successes in quantum theory, such as the virtual oscillator, while revealing through its own shortcomings the limitations of the wave theory of light in the interaction of light and matter. After its publication, Darwin's theory was widely discussed amongst his colleagues as the competing interpretation to Compton's in X-ray scattering experiments. It also had a pronounced influence on John C. Slater, whose ideas formed the basis of the BKS theory.
\end{abstract}

\section{Introduction}

Charles Galton Darwin mainly appears in the literature on the development of quantum mechanics in connection with his early and explicit opinions on the nonconservation (or statistical conservation) of energy and his correspondence with Niels Bohr. He is a marginal figure nudging Bohr's intellectual direction by providing ammunition against the photon. However, Darwin was not "on the fringe" of quantum physics (Hendry, 1981) - his ideas were in line with the main defenders of the wave theory of light and his contributions were meaningful and respected by the physics community. Thus, Sánchez-Ron was correct in stating that Darwin's work "has received a rather cursory treatment" apart from several manuscripts on the state of physics (Sánchez-Ron, 1993). Sánchez-Ron, and subsequently Navarro (Navarro, 2009) and Jordi Taltavull (Taltavull, 2017), have amended this situation further by providing detailed descriptions of Darwin's ideas. However, there is still only limited examination of Darwin's published papers on quantum theory in literature. Aiming

\footnotetext{
a e-mail: benjamin@fhi-berlin.mpg.de
} 
to add another piece to Darwin's scientific biography, this article examines his 1922 publication A Quantum theory of Optical Dispersion (Darwin, 1922b, 1923b) as a concrete, but overlooked step in the conceptual development of dispersion theory. His paper influenced his colleagues across Europe and offered clues how to translate classical systems into their quantum mechanical counterparts. This work also provided insight into the nature of light.

The debate on the structure of radiation was always at the center of the development of quantum mechanics. In 1900, Max Planck incited the quantum revolution by using resonators to express the correct energy distribution for black body radiation (Hendry, 1980a; Büttner, 2003). By 1913, it was apparent that the interaction of light and matter proceeded via discontinuous changes in energy (although arguments for continuous processes were still defended). However, the form the quanta took during propagation was not clear. Were they directed with defined energy and momentum or wave-like as they dispersed in free space, as the majority of physicists believed (Stark, 1909a,b)?

Tightly bound to the debate on the nature of light was the investigation of the atom and the exact internal mechanism by which radiation was absorbed and emitted. In 1913, Niels Bohr postulated a quantum interpretation of this mechanism in his trilogy of papers on atomic structure (Bohr, 1913). However, his reliance on electron orbits was incompatible with observation. The periodic movements of the electrons (the basis of the classical theory of the interaction of light and matter) did not have the same frequencies in Bohr's stationary states as the radiation observed during absorption and emission processes (expressed through Bohr's frequency condition, $\left.E_{m}-E_{n}=h \nu_{m n}\right)$. By the early 1920 s, some relief was provided when a new concept emerged: the emission and absorption of atoms resembled the behavior of a collection of classical harmonic oscillators. At the same time, the wave-based theories of light propagation were contested on the basis of theoretical and experiment results supporting a corpuscular theory of radiation. Notably, in 1916, Andrew Millikan verified Einstein's 1905 equation for the photoelectric effect (Millikan, 1916). For several years, however, the physics community remained far from convinced of these results.

At the end of 1910s and into the 1920s, there was reason for distress. Would physicists find a modified approach to electromagnetism and mechanics to describe quantum phenomena or was an entirely new theory required? The acute expression of this predicament was how the structure of radiation was to be reconciled with the mechanism of excitation of the atom. In 1916, Albert Einstein offered one solution with his $\mathbf{A}$ and $\mathbf{B}$ coefficients describing absorption as well as induced and spontaneous emission. The interaction between corpuscles of light and atoms was described by probability (in the sense of statistical mechanics) while obeying the strict conservation of energy and momentum (Einstein, 1916). In other circles, the disjunction between discontinuities and continuous waves resulted in the embracement of acausality; the conservation of energy and momentum in atomic processes were required to be statistically valid. Observed physical laws only emerged as causal at the macrolevel. One of the first public confrontations with the consequences of statistical energy conservation was put forward by Charles Galton Darwin in 1922. Simplistic in some ways, clairvoyant in others, his theory of optical dispersion formed a significant, often unrecognized step in the interaction of light and matter. The mechanism of interaction was similar to Einstein's (Darwin did not state this connection explicitly), in that an atom in an electromagnetic field had a finite probability of emission proportional to the incoming field. ${ }^{1}$ In Darwin's model, however, probabilities depended on the time-rate of change of the field and the incoming and outgoing radiations were

\footnotetext{
${ }^{1}$ Proper interpretations of Einstein's coefficients for spontaneous emission allow for translation between Darwin's theory and the dispersion theory of Ladenburg and Reiche.
} 
waves. Relying on an abstract, mathematical description of the atom, his theory also contributed to the transition from electron orbits to harmonic oscillators.

Within three years, the validity of theories based on non-conservation had been disproven by data from collision experiments between X-rays and atomic electrons. As the quantum theory of optical dispersion developed, they were replaced by newer theories incorporating these results. This change drove the frontiers of the "old quantum theory" in the early 1920s and resulted in the mature mathematical expression of the harmonic oscillator. As a heuristic device, the harmonic oscillator provided insight and motivation for the final formulation of matrix mechanics in 1925 (Jammer 1966 [page 181]; Mehra 1982c [page 170]; Blum 2017).

\section{Before the war}

Charles Galton Darwin was born on December 18, 1887 in Cambridge into a wellestablished scientific family. He was the son of George Howard Darwin, an astronomer and mathematician, and grandson of the eminent naturalist Charles Robert Darwin. He concluded his studies at the University of Cambridge in 1909 with a pronounced belief in the power of applying mathematical models to physical systems, a consequence of the strong tradition of the Mathematical Tripos at the university (Thomson, 1963; Sánchez-Ron, 1993; Navarro, 2009). ${ }^{2}$ Before World War I, Darwin published several important papers on classical physics as well as the application of classical physics to atoms and the interaction of radiation and matter in a quantum context (Darwin, 1912a, 1913, 1914; Moseley, 1913). It was his 1912 paper on $\alpha$-rays, published while Darwin was at Ernest Rutherford's laboratory (Fig. 1), that captured the attention of Niels Bohr, who was also at Manchester at the time Rutherford introduced his nuclear atomic model. Bohr did not find the mathematical or conceptual execution of Darwin's paper to be satisfactory, as he wrote to his brother Harald on June 12, 1912, but, at a time when his own ideas on atomic structure were nearing fruition, he did not brush it aside without consideration (Mehra 1982a [page 185]). This would not be the only time a daring, but flawed idea of Darwin's led Bohr to a more progressive position.

Throughout this period, Darwin remained a stalwart of classical physical concepts, but he was aware of the controversy stirred by Planck's derivation of the radiation law (Sánchez-Ron, 1993). In his 1912 manuscript, The Theory of Radiation, he explained how, with respect to new developments, the electromagnetic theory was incomplete. The remedy, he claimed, while considering the equipartition of energy and Planck's ideas on quantization, was most likely found in the interaction of light and matter (Darwin 1912b; Beller 1999 [pages 131-134]). "As guidance in formulating a [new] theory [of radiation]," he wrote, declaring his beliefs at the time, "we have the conservation of energy and momentum and the known equations when a number of electrons move together [page 41]."

Beyond the ideas extending from Planck's radiation law, Darwin was likely exposed to other perspectives critical of the conservation of energy before he left for war. For example, he was a well-known admirer of Henri Poincaré's and translated the French mathematician and physicist's On The Theory of Quanta into English (Poincaré, 1912; Darwin, 1919d). ${ }^{3}$ In that essay, Poincaré remarked on the type

\footnotetext{
${ }^{2}$ These three publications supply more perspective on Darwin, his pre-World War I "classical period" and his turn toward the non-conservation of energy.

${ }^{3}$ There is confusion as to when Darwin translated this manuscript. His notes at the end of the translation are dated Oct. 1919. The American Philosophical Society library also dates the translation to 1919 although an online finding aid puts the year at 1912. Max Jammer puts the year at 1914 (Jammer 1966 [page 171]).
} 


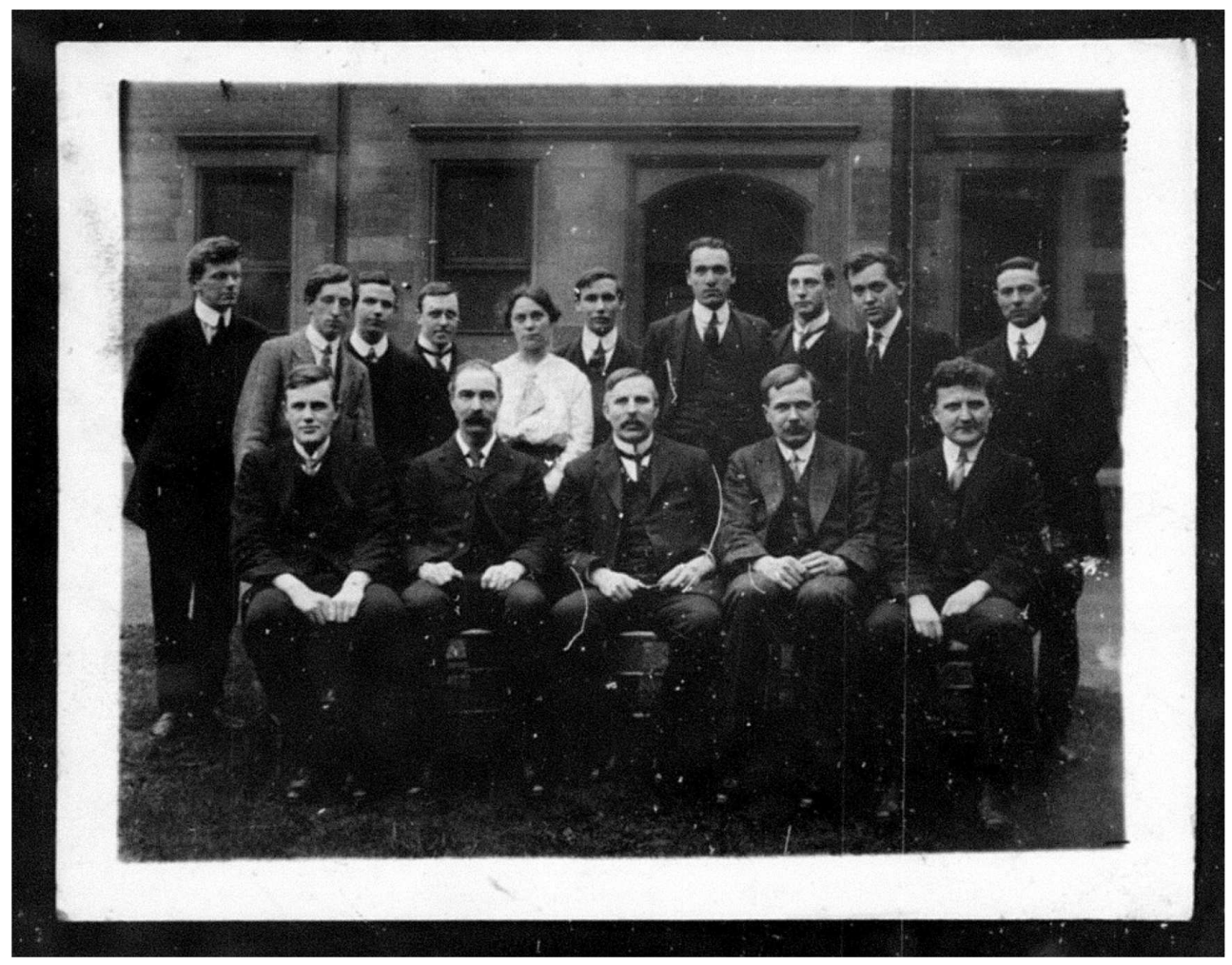

Fig. 1. C.G. Darwin (front row, second from right) with Ernest Rutherford (to Darwin's right) and other members of Rutherford's laboratory in Manchester about 1912. Source: C.G. Darwin Papers, American Philosophical Society, Philadelphia, PA, USA.

of theory required to derive Planck's equation and that it must rely on a quantum hypothesis of discontinuities. Darwin would question this idea in 1919 (Darwin, 1919a). However, Poincaré is more specifically critical toward energy and Energetics in a passage from the 1905 translation (not by Darwin) of his La Science et l'Hypothèse (Poincaré, 1902, 1905) [Chapter 8]. He wrote:

...the sum of the kinetic and potential energies is constant. This is the principle of the conservation of energy [...] The definitions of the two kinds of energy would raise difficulties [in complicated cases] almost as great as those of force and mass [...] how, therefore, can we distinguish the two parts of the energy? But there is more than this. How can we define energy itself? [...] We must take account, not only of mechanical energy properly so called, but of the other forms of energy...[which] would be all right if [they] were absolutely distinct...But this is not the case [...] Of the principle of the conservation of energy there is nothing left then but an enunciation: - There is something which remains constant [italics in original English translation]. In this form it, in its turn, is outside the bounds of experiment and reduced to a kind of tautology. It is clear that if the world is governed by laws there will be quantities which remain constant. Like Newton's laws, and for an analogous reason, the principle of the conservation of energy being based on experiment, can no longer be invalidated by it. 


\section{Toward non-conservation}

Dalton was a competent physicist who, before World War I, remained true to his classical scientific upbringing and was skeptical of Planck's theory. When Darwin went to war in August of 1914, he became detached from the tumultuous developments in physics. It was the last time he would see of that old world. In 1915, he was involved in the battle at Loos and continued sound ranging from 1916 to 1918 in France on the front lines where he "had great fun devising complicated electrical connections," though he eventually tired of the work. In April 1918, his unit was badly shelled and gassed by the German's at Armantières. He returned to England later that year and left the army in 1919 (Darwin, 1919c).

Upon his return, Darwin was acutely aware of his own deficiencies in physics due to his absence. His knowledge of the literature had lapsed and significant changes had taken place. Millikan's verification of Einstein's equation for the photoelectric effect lay several years back as did Einstein's introduction of his $\mathbf{A}$ and $\mathbf{B}$ coefficients. Light corpuscles had been endowed with energy and momentum. The quanta themselves were now more accepted in England, but there were still no definitive answers. Darwin had returned to a discipline in crisis and he could feel it. He jumped back in with a notable interest in absorption and emission spectra. This included "a paper lent to me for a few days by Rutherford... which was written under your [Bohr's] auspices by Kramers." Despite the influence of this contribution from Kramers' dissertation on Darwin (Kramers, 1919), it would be several years before his own ideas on the quantum atom came together.

In 1919, documented through correspondence with Niels Bohr and unpublished writings, his attitudes toward classical and quantum physics began to change from those expressed before the war (Darwin, 1912b). Remaining a supporter of the wave theory of light but no longer able to deny the discontinuities in absorption and emission processes, he felt the answer lay in statistical energy conservation. The case against classical conservation had become "quite overwhelming." These documents (Darwin, 1919c,a,b; Bohr, 1919) are discussed often in the literature (Jammer, 1966; Klein, 1970; Stuewer, 1975; Mehra, 1982b; Stolzenburg, 1984; Sánchez-Ron, 1993; Navarro, 2009; Kragh, 2012), Taltavull (2017) [pages 397-404] and are referred to the interested reader for further details on Darwin's transition. ${ }^{4}$

Here, an excerpt from Critique on the Foundations of Physics (Darwin, 1919a) will suffice to describe Darwin's approach to the new reality in physics (which often paralleled Bohr's thinking). It also illustrates his attitude toward Planck's theory and the resulting possibility of the light quantum. "The Planckian discontinuity," he wrote,

...can only be a statistical description of some other [phenomena] of an entirely different kind. As soon as we attempt to give it precision we encounter the stumbling block 'frequency' [\$4][...] Thus experimental evidence points to the inexact conservation of energy, while arguments for the necessity of quanta collapse unless conservation is exact, so I maintain that the most promising outlook for a reconciliation of our difficulties is to suppose that energy is not exactly conserved [§5].

Recalling also Bohr's difficulties reconciling the orbital frequencies of the electrons in stationary states with the radiation emitted from an atom, a set of ideas was emerging that Darwin would use to construct his dispersion theory. It would be devoid of light quanta and the emitted radiation independent of a corresponding

\footnotetext{
${ }^{4}$ Also of interest on the general development of ideas of non-conservation are Forman (1971); Hendry (1980b)
} 
electron movement or behavior. ${ }^{5}$ Prior to Darwin's publication, however, the first salient step toward a quantum-theoretical dispersion theory was taken by Rudolf Ladenburg in 1921 (Ladenburg, 1921) after attempts by Debye (1915), Davisson (1916) and Sommerfeld (1918) had failed. The earlier theories were based on perturbation approaches, which calculated only the Fourier components of the electron motions (Mehra 1982b [pages 632-638], Mehra 1982c [pages 170-172], Jammer 1966 [pages 188-191], Hendry 1984 [pages 46-48], Darrigol 1992 [pages 224-225], Kragh 2012 [page 338]). Ladenburg began with the classical dispersion theory of Lorenz and derived an analogue quantum-theoretical expression for the number of dispersion electrons. Instead of electron oscillations induced by incoming radiation, the interaction of light and matter now described an Einstein-like electron excited statistically by the incoming radiation and relaxing back to its ground state. Ladenburg did not depend, in a classical sense, on a distinct atomic structure as Bohr had done with his electron orbits. The number of dispersion of electrons calculated by Ladenburg implied a quantum-theoretical polarizability, $\alpha$ :

$$
\alpha=\frac{c^{3}}{32 \pi^{2}} \sum_{k} \frac{a_{k i}}{\nu^{2}\left(\nu_{i k}^{2}-\nu^{2}\right)}
$$

where $\nu_{i k}$ are the atomic absorption frequencies and the $a_{i k}$ are the Einstein coefficients for spontaneous emission from the higher state $k$ to the state $i$ (Mehra 1982c [page 171]). The sum covers excitation to all states above $i$ and represents an initial mathematical incarnation of the harmonic oscillator which would become so prolific and "virtual" - by 1924. In 1923, Ladenburg and Fritz Reiche published a more rigorous theoretical justification of their dispersion relation and presented several relevant applications; the results, they argued, were based on the fact that the dispersion electrons could be described by the behavior of "Ersatzoszillatoren," each representing the frequency of a specific atomic transition (Ladenburg, 1923). Ladenburg's theory contained statistical excitations of the atom in the sense of Einstein and was conceptually different from the statistical approaches that led the authors of the future BKS theory to non-conservation. Einstein, who regretted the appearance of probability in his theory, applied it in the sense of statistical mechanics. That is, he expressed the result a large number of processes, which could not be individually observed, by describing them statistically. However, causality and strict energy conservation were assumed to hold in each "micro"-interaction (Jammer 1966 [page 170], Capellmann 2017). Thus, Ladenburg's theory did not imply a statistical conservation of energy.

In comparison, Darwin's dispersion theory was progressive in terms of foreshadowing the BKS theory-it relied on statistical conservation of energy in the BKS-sense-but was regressive in other aspects.

\section{Darwin's 1922 theory of optical dispersion}

Darwin had shown an interest in the quantum-theoretical field of dispersion in 1919 but had not pursued it immediately. During this time, there was also a lack of correspondence between Darwin and Bohr. Their relationship was rekindled in 1922, likely because of the pending and then actual meeting of the two in Cambridge that year (Bohr, 1922b,c). While they still shared their general approach to quantum concepts,

\footnotetext{
${ }^{5}$ The lack of reliance on explicit electron motions is also discussed at the beginning of $\S 5$ of Darwin (1919a) in a well-known passage in which Darwin conceives the absurdity "of every electron containing a complicated system of clockwork which can be wound up by the incoming radiation..."
} 
the exact translation to theory exposed fissures in their thinking that were laid bare by Darwin's 1922 dispersion theory. Their renewed contact exemplified the critique, pointed discussion and sharing of ideas that would accompany the development of quantum physics for the next several years. The nature of light continued to be a point of contention and experimental evidence in the early 1920s remained inconclusive (Klein, 1970; Stuewer, 2014). As controversial as Darwin's wave-based theory was, it could not yet be dismissed on experimental grounds.

Ladenburg's use of harmonic oscillators in his dispersion theory, published the year before Darwin's, had considerable impact on the description of the coupling mechanism between atoms and radiation. "[Es] muß angenommen werden," wrote Bohr just as Darwin's theory was published, "daß dieser Mechanismus...bei Bestrahlung des Atoms in einer solchen Weise wirksam wird, daß die Gesamtreaktion einer Anzahl von Atomen dieselbe ist wie die einer Anzahl von harmonischen Oszillatoren in der klassischen Theorie...Ein derartiger Gedankengang ist zum erstenmal in einer Arbeit von Ladenburg näher verfolgt...Bohr (1923)." It was not the end of the dispute on electron orbits versus harmonic oscillators. Into 1925, although the tide was turning against the viability of orbits, anschauliche atomic models continued to be used and debated. The question was whether the description of atoms was to be realistic or formal? A pertinent example is Werner Heisenberg's core model theory to explain the anomalous Zeeman effect and Wolfgang Pauli's outspoken critical response (Heisenberg 1925b,a; MacKinnon 1977; Serwer 1977; Mehra 1982c [pages 198-205]; Hendry 1984 [pages 49-64]; Beller 1999 [page 53]; Kragh 2012 [pages 322-325]; Darrigol 1992 [pages 240-241]). Furthermore, the use of Einstein's theory in Ladenburg's derivation and its relationship to the light quantum did not escape Bohr. He reacted to this in 1923 by claiming the non-conservation of energy in individual atomic events.

In 1922, therefore, Darwin's dispersion theory was cutting-edge. It was anticlassical in that it was based on an abstract (mathematical) atom as the source of a secondary wavelet produced by an unspecified set of oscillators. It did not rely on electron orbits or any model of a physical atom (at the time there were many of these models (Forman, 1970)). The use of the classical wave theory of light, however, was much the opposite. Combining the two, he showed how the statistical conservation of energy could be explicitly applied in easing a disparate situation in the interaction of light with matter.

Darwin examined a monochromatic wave moving along the $z$-axis, polarized along the $x$-direction and incident upon a group of $N$ quantum atoms at the origin. Each atom reacted to the incident radiation by sending out an expanding spherical wavethe same as would be emitted in free emission. It was "inconceivable" to him that the effect could be anything else and was in direct contradiction to Einstein's 1916 description of directed emission (Klein, 1970). This meant Darwin's emission process could not impart energy or momentum to the atom, a constraint which later caused difficulties when compared with experimental data.

The electric field vector (which Darwin called the "electric force") of the spherical wavelet had components in the three directions given by:

$$
\begin{gathered}
E_{x}=\frac{r^{2}-x^{2}}{r^{3}} f(t-r / c) \\
E_{y}=\frac{x y}{r^{3}} f(t-r / c) \\
E_{z}=\frac{x z}{r^{3}} f(t-r / c)
\end{gathered}
$$


The electric force was equal to zero at the two poles ( $x$-axis) and was otherwise proportional to the cosine of the latitude, while the magnetic force lay in the circles of latitude. Darwin regarded the contribution in the $x$-direction and subsequently focused only on equation (2); this simplified the model but did not effect the general elements of the theory, he claimed. Borrowing from Bohr, Darwin asserted there was a certain probability that an atom would emit a secondary wave equal to equation (2) and that the resulting outgoing wave could be determined using superposition. He set the probability of secondary emission within a time $d t$ proportional to the time-rate of change of the electric force on the atom,

$$
A_{n}\left(\partial E_{x} / \partial t\right) d t
$$

Einstein, in contrast, set the probability of interaction proportional to the radiation density. Darwin chose $f$ in equation (2) to be a standard wave, a choice critical to supporting the wave theory of light:

$$
f=a_{n} e^{-\lambda_{n} t} \cos k_{n} t
$$

Here $A_{n}, a_{n}$ and $\lambda_{n}$ depended only on the atom in question and not on the incident force. The $n$ indicated differing pathways to emission, each with their own probability. $\lambda$, taken as small, was a damping coefficient present so the effects of secondary emission vanished at infinity.

Setting the incoming wave equal to

$$
E_{x}=H_{y}=F \cos p(t-z / c)
$$

Darwin calculated the number of atoms excited in an interval $d t$ to be

$$
N A_{n}\left(\partial E_{x} / \partial t\right) d t=N A_{n}(-F p \sin p t) d t
$$

by multiplying equation (5) by the number of atoms, $N$, and then substituting $E_{x}$ from equation (7).

Next, Darwin considered the effect of the secondary emission at some point $r=$ $(x, y, z)$ at a time $t+(r / c)$. Accounting only for the atoms excited before time $t$, the number of atoms emitting in the interval $d s$ at the time $t-s$ was, analogous to equation (8),

$$
N A_{n}(-F p \sin p(t-s)) d s
$$

All these atoms would have emitted a wave at time $t$ analogous to equation (6) characterized by

$$
f=a_{n} e^{-\lambda_{n} s} \cos k_{n} s
$$

The waves were emitted at time $(t-s)$ and observed at time $t$ so that the total time, $s$, during which they had traveled is found in equation (10) instead of the general time, $t$, in equation (6).

Summing all the waves together (number of emitting atoms from Eq. (9) multiplied by the emitted wave of each from Eq. (2), with $f$ taken from Eq. (10), and integrating over time with $s \rightarrow \infty)$, the effect at $r=(x, y, z)$ at time $t+(r / c)$ was, 
with $\lambda_{n}$ small: $^{6}$

$$
\begin{aligned}
E_{x} & =-N A_{n} F p\left(-\frac{r^{2}-x^{2}}{r^{3}}\right) \int_{0}^{\infty} \sin p(t-s) d s a_{n} e^{-\lambda_{n} s} \cos k_{n} s \\
& =N A_{n} a_{n} \frac{r^{2}-x^{2}}{r^{3}} F \frac{p^{2}}{k_{n}^{2}-p^{2}} \cos p t
\end{aligned}
$$

From this Darwin, like Ladenburg, determined a quantum-theoretical expression for the number of dispersion electrons by setting $N_{n} e^{2} / m c^{2}$ in the classical relation equal to $N A_{n} a_{n}$ to arrive at:

$$
\frac{3\left(\mu^{2}-1\right)}{\mu^{2}+2}=\sum_{n} \frac{4 \pi N c^{2} A_{n} a_{n}}{k_{n}^{2}-p^{2}}
$$

where $\mu$ is the index of refraction and $\alpha=\frac{3\left(\mu^{2}-1\right)}{4 \pi N\left(\mu^{2}+2\right)}$ (for direct comparison with Eqs. (1) and (14)). For a proper equivalence between the $A_{n}$ and $a_{n}$ to Einstein's coefficient for spontaneous emission, $a_{k i}$, Darwin's result agreed with Ladenburg's equation (Ladenburg 1923, Mehra 1982b [page 637]). The ansatz of a probabilistic secondary wavelet was, however, quite different from Ladenburg. In Darwin's theory, the addition of all the contributions averaged out the frequency of waves stemming from the atoms and left only the frequency of the incident wave. He wrote, "the atoms act as Fourier analysers, sort out the harmonic components of an arbitrary incident wave and refract each component in the proper degree. In all cases the characteristic frequency with which the [secondary] waves are really emitted will entirely disappear by averaging." Although structurally (mathematically), Darwin's result relies on a set of harmonic oscillators, he did not explicitly state this in setting up his derivation.

As for the (non-) conservation of energy, the incoming wave excited the illuminated atoms with the probability $A_{n}\left(\partial E_{x} / \partial t\right) d t .^{7}$ "It will be necessary to consider the balance of energy which is nearly but not quite exact," a consequence, Darwin wrote, of his simple model. "In any case there is a clear contradiction to the principle of energy, but the phases of the outgoing waves are so adjusted that for cases of pure scattering or refraction, on the average, as much energy goes out as comes in. Thus, the incoming and outgoing waves must be in some kind of phase relationship." ${ }^{8}$ In reviewing his hypothesis, Darwin admitted some aspects were not in agreement with accepted theory. One would be of particular consequence. "As we have made no assumptions as to what goes on inside the atom," he wrote,

we can take over the whole of the dynamics of stationary states. We suppose that an atom is usually in its lowest quantum state. The motions of the electrons will sometimes lead to a favourable configuration, and when

\footnotetext{
${ }^{6}$ This physical scenario may be compared to a passage published later in the BKS paper: "The appearance of these [absorption] lines in the spectroscope is due to the decrease of intensity of the incident waves in consequence of the peculiarities of the secondary spherical wavelets set up by each of the illuminated atoms...Bohr (1924)"

${ }^{7}$ Although the emitted wave was real, the immediate source of energy was not defined. Therefore, there was no need for it to have come from the occupied stationary state, as Bohr would criticize. The sense that the radiation could be virtual came later.

${ }^{8}$ Later, in a letter to the editor of Nature Darwin was more explicit about the phase relationships (Darwin, 1923c). There he wrote, this time in connection with absorption, "it appears to me that this scattered wave, having a phase relationship with the incident wave and determining the balance of energy, is one of the most essential features to be watched in any attempt to work out a quantum theory of absorption."
} 
this occurs in the presence of a changing electric force, there is a chance that the atom may be jerked into a condition in some way associated with one of its higher quantized states. It at once starts radiating with a frequency corresponding to the return from that state to the lowest.

Darwin did not explicitly state that the phase relationship was dependent on the instantaneous emission of secondary radiation. The requirement that "the [secondary] radiation must be immediate," can, however, be seen in the mathematics of his model. He wrote, "it is possible to argue inductively from the observed fact that if incident waves are superposed [on the secondary wave] the result can be found by an addition of their effects..." Darwin supplied no option for delayed emission because a coherent phase relationship would not be possible, were the atoms excited into states with arbitrary lifetimes independent of the frequency of the incoming radiation. He was, however, aware of the consequences of presuming the immediate onset of emission and wrote, in contrast to what he had described earlier in the paper, "the state would not really be stationary at all." This attack on stationary states was prime bait for Bohr to later criticize Darwin's theory, ${ }^{9}$ but, reinterpreted in the hands of J.C. Slater, it also provided Bohr with an escape from a critical physical conundrum.

Furthering his conjecture on the amount of energy released in the interaction, Darwin wrote, "it is rather tempting to suppose that it [the atom] actually goes into the higher quantised state, and then gives a wave of such amplitude and length that, but for the interference with the incident light, it would emit energy $h k_{n} / 2 \pi$." For Mehra and Rechenberg (Mehra 1982b [page 637]), this was akin to introducing the light quantum into the theory. However, at the time Darwin did not accept the light quantum and the use of the term "amplitude" was not compatible with the corpuscular view. It was rather an afterthought and was not critical to the results of his theory. As expressed by Johannes Stark, energy was absorbed and emitted in quantized form, whatever form this may have been. Darwin was more likely speaking of an emitted wave train with a finite total energy, similar to what was later envisioned in the BKS theory (Bohr 1924 [page 788]).

Although Darwin admitted his was still "a very incomplete theory," it was one of the earliest explicitly formulated public endorsements of non-conservation of energy based on statistical behavior at the atomic level. While the proliferation of these ideas prior to Darwin is often discussed in the context of Franz Exner ${ }^{10}$ (supported by Erwin Schrödinger's comments about Exner, Schrödinger 1929, Exner 1909, 1919, Jammer 1966 [pages 169-171], Mehra 1982b [page 537], Stöltzner 1999), there were other pre-Darwin proponents of non-conservation. As Helge Kragh wrote, "the idea of statistical energy conservation was at the time in the air...Kragh (2012) [page 328]." One example was the American physicist and follower of Poincaré, David L. Webster. In his investigation of quantum excitation, absorption and emission phenomena, he concluded in 1920 that energy conservation was statistical in these processes and predicted such descriptions would lead to a quantum theory of dispersion that looked like the classical one. Referring to the passage from Poincaré on page 4 of this paper, he wrote (Webster, 1920):

...every time we deal with a new type of phenomenon, we find or invent a new quantity that we can call energy, and define it so as to make the total energy of the system constant...the law of conservation of energy is not a law, but a postulate. Some time, a phenomenon may arise where this postulate is not advantageous in its most complete form. It seems to

\footnotetext{
${ }^{9}$ See footnote 7 .

${ }^{10}$ While Bohr and Darwin arrived at their statistical ideas of energy conservation and acausality by accepting quantum mechanical observations, Exner began with a statistical approach and worked forward from there to arrive at a causal limit of single particle interactions.
} 
me that this time has come [...] Consequently it seems better to assume that in postulating the existence of stored energy in the oscillator we have carried the postulate of conservation too far. We had better abandon it at this point and postulate a system of equations that give the conservation of energy as a statistical effect only...

Years later, Webster summed up the turmoil in quantum theory in the first quarter of the twentieth century with a lament reportedly common among his colleagues (Webster, 1964). "God ran electromagnetics on Monday, Wednesday and Friday by wave theory, and the devil ran it on Tuesday, Thursday and Saturday by quantum theory."

\section{Reactions to Darwin's theory}

Reactions to Darwin's A Quantum Theory of Optical Dispersion were far reaching among both his experimentalist and theorist colleagues. Some were optimistic, others critical.

Prior to publication, Darwin had sent a draft of his theory to Bohr for consideration and the Danish physicist sent his response two days before Darwin's manuscript went to press (Bohr, 1922a). In the letter, Bohr had several blunt criticisms of Darwin's work (non-conservation was not one of these), although he admitted it had made him reconsider his own pending publication. When the paper was published, however, Bohr had decided to stick with his original ideas while publicly airing the opinions he had originally shared privately with Darwin (Mehra 1982b [page 638]). ${ }^{11}$ He strongly defended his stationary states from Darwin's instantaneous transitions leading to coherent phase relationships between the primary and secondary waves. In the letter, Bohr had also stated that Ladenburg's theory implied "the reaction of the atom [to illumination] corresponds to that of a harmonic oscillator on the classical theory," implying Darwin's theory had not done so. In 1923, Bohr expanded on this, admitting the "paradoxer Gegensatz" that an atom could react by emitting a spherical wave in a coherent phase relationship with the incoming wave because this view was at odds with the stability of the stationary states (Bohr 1923 [page 161]). While the lack of any atomic model, or "black box" ${ }^{12}$ approach to absorption and emission in Darwin's atom is in fact anti-classical, the phase relationship set up via the infinitely short duration of the excited state is very much the picture of the classical oscillating dipole and again demonstrates the fusion of opposing pictures in Darwin's theory. ${ }^{13}$ Beyond the stationary states, which were his main point of contention, Bohr also commented on recent experimental results indicating the dispersion of light was independent of intensity. Darwin's theory could not account for this because the probability of emission was equal to the amplitude of the incoming wave. Ladenburg and Reiche had similar criticisms, although they showed how Darwin's theory could be formally brought into agreement with their own, as different as the two methods of relating classical and quantum theories may have been (Taltavull 2017 [page 413]). While they themselves had not been able to describe the exact mechanism leading to

\footnotetext{
${ }^{11}$ Bohr was referring to Bohr (1923) which he submitted in November, 1922 during the initial exchange with Darwin on dispersion. Bohr had a footnote (page 163, footnote 2) referencing Darwin's work added to his article after it had been accepted for publication.

${ }^{12}$ This view was not shared by all of Darwin's contemporaries. The opinions of Ladenburg and Reiche as well as Adolf Smekal and John C. Slater are discussed below.

${ }^{13}$ Jordi Taltuvall, who gives further details on Bohr's reaction to Darwin's theory (Taltavull 2017 [pages 397-414]), also emphasizes that Darwin stepped away from the classical harmonic oscillators in dispersion theory [page 409]. However, I argue this was rather due to his atom behaving like a grouping of nondescript and undefined "Fourier analysers".
} 
the interaction of light and matter, they found Darwin's approach, while not ideal, did offer some insight.

As for Darwin's response to Bohr, already in November of 1922 he had written to explicitly cast doubt on the stationary states as he would do in his publication. "I think that the atom goes to the upper state and starts radiating at once Darwin (1922a) (as published in Stolzenburg (1984) [page 17])." There is no further surviving private correspondence on the subject between the two men. ${ }^{14}$ However, in June of 1923, Darwin published a letter to the editor of Nature in his familiar hesitant and conciliatory style addressing some points of his dispersion theory (Darwin, 1923c). "In a letter published in Nature on December 23, 1922," he wrote, "I put forward a theory of dispersion which attempted to begin the reconciliation of the quantum theory with the wave theory. I have received several letters criticising my hypothesis, and it seemed to me that it would be well to acknowledge the justice of the criticism."

Darwin tackled the problem of dispersion of low intensities via a mathematical formality, but the solution came at a cost. The scattered light was dependent on the product of two factors: the probability of excitation, $A_{n}(d \partial E / \partial t) d t$ (Eq. (5)) and the amplitude of the standard wave, $a_{n}$. "It is only necessary to alter the assumptions by taking $A_{n} d t$ as the probability and $a_{n}(\partial E / \partial t)$ as the amplitude of the scattered wave..." While this was the form of the theory with which Darwin had begun to work, he regretted the failure of the simple outgoing standard wave because he was no longer able to "unite the classical theory with the simple form of the quantum theory." As for the criticism of the phase relationship between incoming and outgoing waves, Darwin insisted upon its necessity.

The note to Nature, was, as the title indicated, really about the confrontation of the wave theory and quantum theory. Darwin wrote,

It must be taken as absolutely certain that both the electromagnetic theory and the quantum theory are valid in their respective fields, and equally certain that the two descriptions are incompatible. We can only conclude that they are parts of an overriding system, which would give rise to mathematical formalæ identical with those of the present theories. It is true that from the present theories predictions can be made which are verified; this does not confirm the physical pictures associated with those theories, but only shows that the limits of their validity have not been reached $[\ldots]$ it is natural to suppose that the complete picture will resemble the classical theory much more closely than it will the quantum theory.

Adolf Smekal, a proponent of the photon, also voiced theoretical objections in 1923 in a set of two notes on the nature of the light quantum and the quantum theory of dispersion (Smekal, 1923a,b). ${ }^{15}$ The main advantage to Darwin's theory was that "weitgehend unabhängig von der genauen Fassung gewisser Einzelheiten gelangt man...zu einer Dispersionsformel, welche...an Stelle der klassisch-elektromagnetischmechanischen Eigenfrequenzen der Molekülsorte deren Quantenfreqenzen enthält." Smekal, however, went on to question the imbalance of energy as well as the wave nature of light in the aether (which was not experimentally verifiable). The wavelength of the emitted radiation, he argued-this was the cause of interference phenomena and a main argument for the wave theory-lost its classical meaning in the quantum picture. The classical value was the result of dividing the frequency by the speed of light. Quantum mechanically, however, the frequency no longer had any classical relationship to the oscillations of the electrons in the atom and was defined only as a "Zahl von

\footnotetext{
${ }^{14}$ A letter from April 30, 1923 from Darwin to Bohr discusses only the possibility of Bohr visiting Edinburgh (Darwin, 1923a).

${ }^{15}$ Smekal, of his own admission, had already tried and failed to formulate a theory based on the same assumptions as Darwin. Jordi Taltavull provides further details on Smekal's background and reaction to Darwin (Taltavull 2017 [pages 414-419]).
} 
der Dimension $\mathrm{sec}^{-1}$ " through Bohr's frequency condition. Smekal then questioned Darwin's stationary atom. According to Einstein's 1916 theory, a stationary atom (as in Darwin's theory) could only be in thermal equilibrium with an electromagnet field if that field were monochromatic at the exact atomic spectral frequencies. Otherwise, a violation of the second law of thermodynamics would result at the macro-level. "Mit diesem Ergebnis scheint uns-selbst abgesehen von jedem auf die Benutzung der Wellentheorie gegründeten Einwand-der oben erwähnten Darwinschen und jeder ähnlichen Dispersionsbetrachtung das Urteil gesprochen."

While the comments of Bohr and Smekal amounted to theoretical wrangling, for which there was not yet a satisfactory solution, Darwin's theory was also applied to experimental results.

In 1923, Robert W. Wood and Alexander Ellet sought assistance from Darwin in understanding their experiments on the emission of polarized fluorescent radiation from mercury vapor (Wood, 1922, 1923). Exposing the vapor to monochromatic, resonant radiation from an electric arc, they studied the amount of polarization resulting from different geometries and magnetic field strengths. "We submitted our results to Dr. Charles Darwin," they wrote, "who made some very valuable suggestions in regard to the theory of the effect." At the time of submission in April 1923, they were satisfied with "Dr. Darwin's way of looking at the problem." Darwin himself, often his own best critic, was no longer satisfied in June when his second letter to the editor appeared in Nature (Darwin, 1923c):

Rather perversely the phenomenon which causes almost insuperable difficulty is the one which is most satisfactory on either the classical or the quantum theory, and that is the phenomenon of resonance radiation, as exhibited in Wood's work with mercury vapour. On my hypothesis the vapour ought to be excitable by light of wave-lengths different from its own, instead of requiring a very exact adjustment in the incident light, as it in fact does. It seems possible that a satisfactory modification of the hypothesis might result from a study of this failure.

One of the sticking points was again the phase relationship-Wood and Ellett's results, Bohr had argued, could be explained by the finite duration of stationary states, allowing no phase relationship between incoming and outgoing waves in the sense of Darwin's theory. Darwin's explanation of the phenomenon observed by Wood and Ellet was also challenged by Wilhelm Hanle (Hanle, 1923); the correct explanation was given by Werner Heisenberg in a paper in which he also demonstrated the advantages of virtual oscillators over orbital models (Heisenberg 1925b, Hendry 1984 [pages 61-62]).

In 1923, despite the failure in connection with Wood's results, Darwin's theory was also at the center of efforts to interpret current experiments on the structure of electromagnet radiation during interactions with matter (Stuewer 1975 [pages 243-244]). It was the old question: wave or corpuscle? The problem was being investigated by C.T.R. Wilson, Walther Bothe and Arthur H. Compton in their famous experiments on the collision between X-rays and electrons. In discussing his results, Wilson made a direct comparison between Darwin's and Compton's (pre-1924) interpretations of X-ray scattering (Wilson, 1923). ${ }^{16}$ Wrote Wilson,

Compton (Compton, 1922) points out that if there is a type of scattering which a whole quantum of radiation is dealt with by one electron of the atom, this electron may be expected to receive the whole momentum, $h \nu / c$, carried by the radiation. If we suppose that the scattered radiation

\footnotetext{
${ }^{16}$ Wilson does not explicitly attribute the theory of an expanding secondary wave to Darwin. See, however, Compton (1922), Stuewer (1975) [pages 243 -244], Mehra (1982b) [page 609].
} 
is emitted by the electron in all directions-not localised in a bundle-then the electron will gain by the scattering process a momentum, $m u=h \nu / c$, in the forward direction and a kinetic energy $\frac{1}{2} m u^{2}=\frac{1}{2} h \nu u / c$.

However, in applying the theories to the "fish tracks" resulting from the ejection of K-electrons from light elements, Wilson could not reach a definite conclusion:

The agreement between the observed phenomena and these applications of Compton's theory lends strong support to that theory. It is a question of great interest whether the quantum of radiation scattered by an electron is emitted in all directions (with a continuous wave front) as assumed above, or in one direction only as Compton suggests. In the latter case the direction and magnitude of the resultant momentum of the electron will depend on the direction in which it emits radiation.

It was not until 1924 that Compton (who had been in conversation with Darwin and Bohr on the subject (Compton, 1924a)) and John C. Hubbard published convincing evidence on the nature of X-ray-electron collisions. It had been a decision between the corpuscular light quantum and Darwin's wave (Stuewer, 1975). The reason Wilson's interpretation had been left open was that the short-range electron tracks he had observed were always in the forward direction. This result, Compton wrote, was "in better accord with the interpretation of the quantum suggested by C.G. Darwin...By studying the motions of the recoil electrons it should be possible to choose between these two forms of the quantum hypothesis (Compton, 1924b)." Not only did Compton and Hubbard's experimental results point toward the corpuscle, but their theoretical considerations showed the recoil electron tracks predicted by Darwin's theory were too small (the result could also have been obtained from Wilson's data). Compton and Hubbard were, therefore, led to their famous conclusion, "that each quantum of scattered X-rays is emitted in a definite direction." As for Walther Bothe, whose results, along with Wilson's, had served as motivation for Compton, he did not contemplate Darwin's theory in 1923-at least not in his publications (Bothe, 1923a,b). Instead, he relied on the work of Compton and the theory of Peter Debye (see, for example Bothe 1923b [page 250, footnotes 1 and 2]). However, in 1923, the experimental evidence had not yet convinced him of the veracity of those theories, either.

Because Darwin's theory of dispersion depended on a precise description of the propagation of electromagnetic radiation in free space, the collision results all but sealed its fate in 1924. The wave nature of light in interactions with matter was no better off. The final evidence came in 1925 when Bothe and Hans Geiger published the results of their double-needle experiments showing the coincidence between scattered X-rays and recoil electrons (Bothe, 1925a,b; Fick, 2009) and Compton and Alfred Simon's cloud chamber results showed the conservation of energy and momentum held at a rate higher than predicted by the theory of Bohr, Kramers and Slater (Compton, 1925; Bothe, 1926). It was not only Darwin's ideas that were shown to be untenable; the BKS theory, too, had to be abandoned (Darrigol 1992 [pages 246-255]).

\section{Influence on John C. Slater}

Darwin's theory played a prominent role with respect to the development of virtual oscillators, the nature of Bohr's stationary states and the line width of emitted radiation during discontinuous transitions. It also made clear the consequences of accepting the statistical conservation of energy (Darrigol 1992 [pages 219-221]). John C. Slater, a perhaps unwilling contributor to the BKS theory, was influenced by Darwin's pioneering thinking as the clash between the light quantum and the wave was nearing 
its climax. At the time, Slater thought both the wave theory and the corpuscle had merit. He made crucial advances to Darwin's approach, which "did not bear fruit until after it had been coupled with Slater's virtual oscillator concept (Stuewer 1975 [page 291])." Slater's idea was that a virtual instead of an actual wave was emitted during an electron's sojourn in a particular stationary state with the continuous emission corresponding to all possible transitions (Slater, 1924). It was different than an atom behaving like a group of harmonic oscillators with frequencies equal to the observed atomic emission or absorption frequencies as had been the case for Ladenburg and Darwin and would be for Kramers (Dresden 1987 [pages 44-45]).

J.C. Slater completed his dissertation at Harvard in 1923. It was there that he had been introduced to quantum physics and planned to go to Copenhagen on a fellowship to further his study in the field. However, because of Niels Bohr's plan to travel to the United States, Slater decided to spend time at Cambridge before moving on to Bohr's institute. In England, he was assigned to Ralph H. Fowler, who the year before had published a two-part series on the partition of energy with Darwin (Darwin, 1922c,d). Slater continued to be interested in electromagnetic theory and attempts to bring together photons and waves into one picture as well as the problem of the finite width of emission lines. Classically, this resulted from the condition that $\Delta \nu \cdot \Delta t \sim 1$ and was irreconcilable with what Bohr claimed were instantaneous transitions between stationary states (Slater 1963, Mehra 1982b [pages 542-543]). ${ }^{17}$ In a 1963 interview, Slater claimed he had no success discussing the subject with Fowler, although a letter from Fowler to Bohr in 1925 makes the situation appear less dire: "I am glad that you are hopeful of Sclater [sic]. I thought that he was thinking on sound lines and encouraged him as much as I could-which wasn't much of course (Fowler, 1925)."

Slater, continuing in the interview, then spoke of Darwin who, "actually was much interested in these things [the breadth of energy spectra]. You see, Darwin was writing papers on radiation theory and so on about the time that I got doing it after I was in Copenhagen. In fact, Darwin and I had some slight arguments about some points on this physics, so that I did talk some with Darwin later, but not then." Not then, because, according to Slater, Darwin was not in Cambridge at the same time he was. He was, however, aware of Darwin's work on radiation theory and the overlap in research lends credence to the assertion that Slater's "speculations were in part inspired by ideas due to the Cambridge physicist Charles Darwin... (Kragh 2012 [page 328])" Darwin may have influenced Slater not only not with the probabilistic interpretation of atomic dynamics, but also with respect to the emission line width and coherent phase relationships. These aspects of Darwin's work are reflected in what later became Slater's virtual oscillators. It would be going too far, however, to say that the idea of the virtual oscillators themselves originated with Darwin.

The available sources do not make it clear when Slater came up with his ideas, ${ }^{18}$ but some of his thinking, including the idea of "the activity of the stationary states," was developed in Cambridge (Slater 1924, Kragh 2012 [page 328]). ${ }^{19}$ When he went to Copenhagen, "the idea was perfectly developed... and I wanted to have the wave emitted during the stationary state so as to get it emitted over a long enough period so that it would have a suitable spectral distribution (Slater, 1963)." This is what Darwin had proposed in 1922: an electron may be "jerked into a condition in some

\footnotetext{
${ }^{17}$ As stated in Hendry (1981), Slater's recollections in this interview are not always in accord with the historical record, i.e. his correspondence and publications at the time. Still, the interview is informative.

${ }^{18}$ Darwin is not mentioned in Slater's biography (Slater, 1975).

${ }^{19}$ In discussing Slater at the end of Hendry (1981), Hendry notes the difficulty in identifying the origins of Slater's ideas that led to the BKS theory. "In summary, then, the question as to such sources must remain an open one." While I heed this warning, I would like to complement what Hendry summarized.
} 
way associated with one of its higher quantised states." When this occurred, "it at once starts radiating with a frequency corresponding to the return from that state to the lowest (Darwin, 1922b)." Darwin was referring to actual and not "virtual" radiation as it would appear in the BKS theory and so the immediate onset of radiation had been a point of criticism from Bohr. The energy of a stationary state had to remain constant at the moment the electron arrived in the new state (Kragh 2012 [page 329]). In the BKS theory, the virtual radiation suggested by Slater carried no energy so that the stationary state could remain as such despite the atom radiating immediately. Bohr could have the best of both worlds because the electron's instantaneous transition to another stationary state could now be associated with a finite line width. ${ }^{20}$ The idea that radiation begins immediately from an excited state, however, came from Darwin. It is fitting as well, recalling his education and the tradition of the Tripos at Cambridge, that such a classical electromagnetic attribute like the line width of emitted radiation would be central to Darwin's theory.

Slater published two papers in 1925 which strengthen the argument for the importance of his experience in England and the influence of Darwin. In a letter to the editor of Nature, he was concise (Slater, 1925a). "The theory in this form was developed in England, under the guidance of Mr. R.H. Fowler, to whom my sincerest thanks is due. The essential feature was the emission of the field before the ejection of the corpuscle; that is during the stationary state before the transition. By this device were avoided the difficulties of explaining coherence, of the "size of quanta," of the presence of interference phenomena in weak light." It must be noted that in 1963 Slater claimed, "I just got nothing from Fowler," and had thanked him in the paper because he felt he ought to. Bearing in mind, on the other hand, how Slater talked of Darwin in 1963, there is no reason to doubt a detailed passage from his article in The Physical Review (Slater, 1925b). It is worth quoting at length in consideration of Slater's formulation of the statistical behavior of the atom, immediate transitions and phase relationships. In the first two paragraphs, Slater described Darwin's contributions to his own thinking. In the third paragraph, Slater gave his reinterpretation of these probabilistic concepts of the atom, namely, how the emission of wavelets was to be described in order to incorporate a finite emission time, coherence and the transition to other states, both lower and higher. The atoms began some process of radiation immediately upon entering a stationary state with frequencies corresponding to all other possible transitions. The emitted field was virtual with the transition to a new state marked by a different set of transition possibilities and associated frequencies. The latter was a hallmark of the virtual harmonic oscillators. Slater's work was a natural evolution of Darwin's theory that amended some difficulties of Darwin's formulation. It was, however, also a fundamental reinterpretation.

"The other direction of escape from the conflict between quantum theory and wave theory," wrote Slater,

has been to retain intact the quantum theory and as much of the wave theory as relates to the field, but to discard conservation of energy in the interaction between them. This is the point of view of Darwin (Darwin, $1922 \mathrm{~b}$ ) in a theory of dispersion which he put forward, but which, it is understood he no longer defends. Darwin assumed that by the passage of light over an atom, the atom acquired a probability of sending out a spherical wave train to interfere with the external light, the probability depending on the strength of the incident light. By the cooperation of many of these interfering trains, the familiar phenomena of dispersion could be explained. The reason why such a theory cannot be right is

\footnotetext{
20 "It was just the completion which your [Slater's] suggestion of radiative activity of higher quantum states apparently lent to the general views on the quantum theory with which I had been struggling for years, which made me welcome your suggestion so heartily (Bohr, 1925)."
} 
that, in very weak light, only a very few atoms would be induced to send out wave trains, and these would not be enough to interfere properly...In addition to Darwin's theory, there have been other attempts to treat the radiation field of quantum atoms by classical methods. Bohr (Bohr, 1923) has suggested that atoms must become sources of spherical wavelets when radiation strikes them. Ladenburg and Reiche (Ladenburg, 1921, 1923) have given formulas for dispersion based essentially on the idea of such spherical wavelets. Neither of these suggestions has, however, gone as far as Darwin's theory in setting up a mechanism for the interaction between waves and atoms. ${ }^{21}$

An attempt was made by the writer, in a note to Nature, enlarged upon in collaboration with Bohr and Kramers (Slater, 1924; Bohr, 1924), to contribute slightly to the solution of these difficulties...The views suggested there had foundations similar to those of Darwin, and of Ladenburg and Reiche. It was supposed that energy was of two kinds, the continuously changing energy of the field and the discontinuously changing atomic energy, and that there was no exact conservation, but only a statistical conservation...It was assumed that atoms under the influence of external light were induced to send out spherical wavelets of light, much like those sent out by the oscillators of Ladenburg and Reiche and not entirely dissimilar to Darwin's, and that those spherical wavelets interfered, giving the phenomena of dispersion, interference, etc....

None of these points [in Slater (1924) and Bohr (1924)], as we have seen, was particularly original. But there was one suggestion in the paper, essentially new, which appeared to afford a more reasonable picture of optical phenomena than we had previously had. That was the suggestion that the wavelets sent out by an atom in connection with a given transition were sent out, not as a consequence of the occurrence of the transition, but as a consequence of the existence of the atom in the stationary state from which it could make the transition. On this assumption, the stationary state is the time during which the atom is radiating or absorbing; the transition from one state to another is not accompanied by radiation, but so far as the field is concerned, merely marks the end of the radiation or absorption characteristic of one state, and the beginning of that characteristic of another. The radiation emitted or absorbed during the stationary state is further not merely of the particular frequency connected with the transition which the atom is going to make; it includes all the frequencies connected with all the transitions which the atom could make. Then the atom is under no necessity of knowing what transition it is going to make ahead of time. ${ }^{22}$ In particular, the atom during a stationary state is supposed to be spontaneously emitting radiation of the various frequencies connected with transitions to states of lower energy, and to be capable of absorbing radiation connected with transitions to states of higher energy. Further, a "negative" absorption is assumed, similar to the ordinary absorption, but resulting in increase rather than decrease of the energy in the external field, and with frequencies corresponding to transitions to states of lower energy. Although the atom is radiating or absorbing during the stationary states, its own energy does not vary, but changes only discontinuously at the transitions, as has always been

\footnotetext{
${ }^{21}$ Here again the differing reactions to the dispersion theories in describing an actual, concrete mechanism of the interaction of light and matter are apparent.

${ }^{22}$ This problem also occupied Darwin. See Darwin (1919a) and Darwin (1923c).
} 
supposed. It is quite obvious that the mechanism becomes possible only by discarding conservation.

The suggestion just described was of value in two different ways. In the first place, it furnished an immediate solution of the difficulties concerning dispersion and absorption of weak light...the number of wavelets cooperating to produce the effect would be as great for weak light as for strong. In the second place, the suggestion makes possible a much more definite picture of the process of interaction of light and atoms, in time and space, than had been possible before. Light is emitted or absorbed in a perfectly definite time-the stationary state. In particular, this provides for a theory of the breadth of spectral lines, since that depends on the length of coherent wave trains, or the length of time during which the atom emits a train.

The harmonic oscillators, as formulated in the theories of Ladenburg and Darwin, were not virtual. After Slater they were. He had found a way to bring together coherence and the need for a finite radiation time with the discontinuous properties of atoms.

Slater's characterization of Darwin's work as inspiration for many of his own ideas bridges the gap between Darwin's dispersion theory and BKS, especially in terms of working out the problems of the interaction of light and matter in the wave picture. The use of virtual radiation in the latter, however, produced quite a different realization of the statistical conservation of energy. While both theories were quickly disproven, it is the BKS theory that has remained historically prominent as it "officially sanctioned the dual representation of the atom as simultaneously a quantum system à la Einstein and Bohr and a set of oscillators à la Helmholtz, Lorentz and Drude. This dual picture had been implicit in [Ladenburg's 1921 paper on dispersion] Duncan (2007a)." Or, as Slater put it, the ideas were "not entirely dissimilar" to Darwin's.

As for the dispersion relation itself, there was one additional physical phenomenon that needed to be incorporated: induced emission. This came in 1924 when Hendrik Kramers and, independently, John H. Van Vleck published their theories of optical dispersion (Kramers, 1924a,b; Vleck, 1924a,b), Mehra (1982b) [pages 630-652], Hendry (1984) [pages 43-49], Jammer (1966) [pages 181-195], Kragh (2012) [pages 337-344], Duncan (2007a,b). ${ }^{23}$ It is here we see the "complete" mathematical formulation of the harmonic oscillators, or the "virtual orchestra." For comparison to equations (1) and (13) (which applied to atoms in the ground state), Kramers result for the polarizability, $\alpha$, was:

$$
\alpha=\frac{3 c^{2}}{32 \pi^{2}}\left\{\sum_{l} \frac{a_{l}^{a}}{\left(\nu_{l}^{a}\right)^{2}\left[\left(\nu_{l}^{a}\right)^{2}-\nu^{2}\right]}-\sum_{l^{\prime}} \frac{a_{l^{\prime}}^{e}}{\left(\nu_{l^{\prime}}^{e}\right)^{2}\left[\left(\nu_{l^{\prime}}^{e}\right)^{2}-\nu^{2}\right]}\right\}
$$

where the $a_{l}^{a}$ and $a_{l^{\prime}}^{e}$ are the Einstein coefficients for absorption and induced emission for transitions corresponding to the frequencies $\nu_{l}^{a}$ and $\nu_{l^{\prime}}^{e}$. The second sum described the "negative absorption" (induced emission), a phenomenon foreign to the classical description (Mehra 1982c [pages 172-173]). This formula, wrote Mehra and Rechenberg, "generalized the previous formulas-of Ladenburg and Darwin-by including the additional second term...Mehra (1982b) [page 641]." Kramers' development of the

\footnotetext{
${ }^{23}$ Van Vleck referred to Darwin's theory as the "alternative" to Kramer's harmonic oscillators for decoupling the spectroscopic frequencies from the electron orbits (Vleck 1924a [footnote 24]), writing the idea originated with Slater. This is interesting considering Slater himself referenced Darwin along with Ladenburg and Reiche.
} 
virtual oscillator has been described as the mathematical formulation of the BKS theory, the sums in equation (14) representing the atoms' continuous emission and absorption of virtual radiation corresponding to all possible transitions. It has also been considered a guess based on Ladenburg's (or Darwin's) outcome. It was neither of these, but rather a rational extension of the previous dispersion forumlae which exploited the correspondence principle. However, the BKS theory may have aided in interpreting the nature of Kramer's oscillators, despite their vague description in the 1924 paper (Hendry 1981, Mehra 1982b [641], Darrigol 1992 [pages 225-228], Duncan 2007a).

The development of the quantum theory of optical dispersion also influenced Werner Heisenberg on his way to Umdeutung. However, the mature dispersion theory was mainly a heuristic tool. Heisenberg also relied heavily on efforts to determine quantum transition probabilities, his own multiplication rule for Fourier coefficients and his reinterpretation of the basic quantum condition (Blum, 2017).

\section{Conclusion}

Charles Galton Darwin was part of a generation of physicists forced to reconcile the differences between classical and quantum physics. Darwin's theory of optical dispersion provides a vivid picture of this disjunction in the first half of the 1920s. It formed a significant conceptual step in the evolution of the old quantum theory and presented ways that classical and quantum concepts might be united. Its failure, however, also identified physical assumptions in need of amendment.

Darwin is considered by some to have been "on the fringe" of quantum physics in 1922. This may be partially justified on the basis of his dispersion theory and its relationship to the BKS theory. While BKS is considered an important conceptual step in quantum theory, it elicits differing reactions today (as it did in 1924) with reference to the concrete applicability of its results. If Darwin's only publication in quantum theory had been his paper on dispersion, it may be fair to place him at the periphery and see his theory only as a provocative effort to push the boundaries of physics. He did, however, also publish within the mainstream. In his two publications with Ralph Fowler from 1922, they proceeded according to the adiabatic hypothesis and the correspondence principle to review "the fundamental connexion between classical thermodynamics and statistical mechanics both of classical dynamics and the quantum theory (Darwin, 1922c,d)."

It was not only in the 1920s that Darwin addressed fundamental problems in physics; he confronted them throughout his career. In 1912, he spurred the imagination of Niels Bohr through an admirable, but incorrect theory on $\alpha$-rays. Perhaps because of this, Darwin's risk-taking mindset and bold enunciation of the statistical conservation of energy-and perceived lack of applicable results-have come to define his legacy. However, his work was more significant than is often described. In addition to important publications on classical physics and the old quantum theory, Darwin also made quantum theoretical contributions after the advent of matrix and wave mechanics. Examples include his paper on the wave equations of the electron from 1928 (Darwin, 1928) and his 1931 book The New Conceptions of Matter (Darwin, 1931). Historical studies are incomplete if they summarize Darwin's contributions to quantum theory using anecdotes to describe the difficulties in physics during the first half of the 1920s (Beller, 1999). Rather, Darwin's results from this time in his career exemplify the winding path science must take without the advantage of hindsight, because even incorrect theories often contain a kernel of truth.

Acknowledgements. Open access funding provided by Projekt DEAL. The author would like to thank: Dr. Greg Good at The American Institute of Physics (Grants-in-aid for the history 
of modern physics) and The American Philosophical Society (Franklin Grant) for financial support. Prof. Dr. Robert Schlögl at the Fritz Haber Institute of the Max Planck Society for institutional support and the freedom to travel to complete this research. Prof. Dr. Jürgen Renn at the Max Planck Institute for the History of Science (Dept. 1) for institutional support and suggestions on content and secondary literature. Matthew Rufe and Margaret Applebaum Rufe for the big teas and accommodation during archival research. Dr. Christian Joas and all at the Niels Bohr Archive for supplying archival sources and suggestions for secondary literature. The referees for their exhaustive reviews and constructive criticism. Dr. Christoph Lehner and Dr. Alexander Blum at the Max Planck Institute for the History of Science for suggesting the subject of C.G. Darwin and discussions on the old quantum theory of the 1910s and 1920s.

Open Access This is an open access article distributed under the terms of the Creative Commons Attribution License (http://creativecommons.org/licenses/by/4.0), which permits unrestricted use, distribution, and reproduction in any medium, provided the original work is properly cited.

Publisher's Note The EPJ Publishers remain neutral with regard to jurisdictional claims in published maps and institutional affiliations.

\section{References}

M. Beller, Quantum Dialogue: The Making of a Revolution, University of Chicago Press, Chicago (1999)

A. Blum, M. Jähnert, C. Lehner, J. Renn, Translation as heuristics: Heisenbergs turn to matrix mechanics, Stud. Hist. Phil. Mod. Phys. 60, 3-22 (2017)

N. Bohr, On the Constitution of Atoms and Molecules, Phil. Mag. 116, 1-25, 476-502, 857-875 (1913)

N. Bohr, Draft of an unsent letter to C.G. Darwin, July, 1919, Bohr Scientific Correspondence through 1922, A-D, American Philosophical Society, Philadelphia, PA, USA (1919)

N. Bohr, Letter to C.G. Darwin, December 21, 1922, Bohr Scientific Correspondence through 1922, A-D, American Philosophical Society, Philadelphia, PA, USA (1922)

N. Bohr, Letter to C.G. Darwin, February 14, 1922, Bohr Scientific Correspondence through 1922, A-D, American Philosophical Society, Philadelphia, PA, USA (1922)

N. Bohr, Letter to C.G. Darwin, September 20, 1922, Bohr Scientific Correspondence through 1922, A-D, American Philosophical Society, Philadelphia, PA, USA (1922)

N. Bohr, Letter to J.C. Slater, December 10, 1925, Niels Bohr Archive, Copenhagen, Denmark, Bohr Scientific Correspondence, Folder 317, Item 6: J.C. Slater (1922)

N. Bohr, Über die Anwendung der Quantentheorie auf den Atombau. I. Die Grundpostulate der Quantentheorie, Z. Physik 13, 117-165 (1923)

N. Bohr, H.A. Kramers, J.C. Slater, The Quantum Theory of Radiation, Phil. Mag. 47, 785-802 (1924)

W. Bothe, Elektronenrückstoß, bei der Zerstreung der Röntgenstrahlen und Lichtquantenhypothese, Die Naturwissenschaften 11, 965-966 (1923)

W. Bothe, Über eine neue Sekundärstrahlung der Röntgenstrahlen. II. Mitteilung, Z. Physik 20, 237-255 (1923)

W. Bothe, H. Geiger, Experimentelles zur Theorie von Bohr, Kramers and Slater, Die Naturwissenschaften 13, 440-441 (1925)

W. Bothe, H. Geiger, Über das Wesen des Comptoneffekts; Ein Experimenteller Beitrag zur Theorie der Strahlung, Z. Physik 32, 639-663 (1925)

W. Bothe, Über die Kopplung zwischen elementaren Strahlungsvorgängen, Z. Physik 37, 547-567 (1926) 
J. Büttner, J. Renn, M. Schemmel, Exploring the Limits of Classical Physics: Planck, Einstein, and the Structure of a Scientific Revolution Stud. Hist. Phil. Mod. Phys. 34, 37-59 (2003)

H. Capellmann, The Development of Elementary Quantum Theory from 1900 to 1927, Springer International Publishing, Cham (2017)

H.A. Compton, Secondary Radiations Produced by X-Rays and Some of their Applications to Physical Systems, Bull. Nat. Res. Co. 4, 1-56 (1922)

H.A. Compton, The Scattering of X-Rays, J. Franklin Inst. 198, 57-72 (1924)

H.A. Compton, J.C. Hubbard, The Recoil of Electrons from Scattered X-Rays, Phys. Rev. 23, 439-449 (1924)

H.A. Compton, A.W. Simon, Directed Quanta of Scattered X-Rays, Phys. Rev. 26, 289-299 (1925)

O. Darrigol, From c-Numbers to q-Numbers: The Classical Analogy in the History of Quantum Theory, University of California Press, Berkeley (1992)

C.G. Darwin, A Theory of Absorption and Scattering of the $\alpha$ Rays, Phil. Mag. 23, 901-920 (1912)

C.G. Darwin, The Theory of Radiation, Charles Galton Darwin Papers, American Philosophical Society, Philadelphia, PA, USA (1912)

C.G. Darwin, On Some Orbits of an Electron, Phil. Mag. 25, 201-210 (1913)

C.G. Darwin, The theory of X-ray reflexion, Phil. Mag. 27, 315-333 (1914)

C.G. Darwin, Critique on the Foundations of Physics (also referred to as 'The Basis of Physics'), a draft of a letter to be sent to Niels Bohr, July 1919, Charles Galton Darwin Papers, American Philosophical Society, Philadelphia, PA, USA (1919)

C.G. Darwin, Letter to Niels Bohr, July 20, 1919, Bohr Scientific Correspondence through 1922, A-D, American Philosophical Society, Philadelphia, PA, USA (1919)

C.G. Darwin, Letter to Niels Bohr, May 30, 1919, Bohr Scientific Correspondence through 1922, A-D, American Philosophical Society, Philadelphia, PA, USA (1919)

C.G. Darwin, The Theory of Radiation: Translation of Henri Poincaré's 'Sur la théorie des quanta', Charles Galton Darwin Papers, American Philosophical Society, Philadelphia, PA, USA (1919)

C.G. Darwin, Letter to Niels Bohr, November 23, 1922 (1922)

C.G. Darwin, A Quantum Theory of Optical Dispersion, Nature 110, 841-842 (1922)

C.G. Darwin, R.H. Fowler, On the Partition of Energy, Phil. Mag. 44, 450-479 (1922)

C.G. Darwin, R.H. Fowler, On the Partition of Energy - Part II. Statistical Principles and Thermodynamics, Phil. Mag. 44, 823-842 (1922)

C.G. Darwin, Letter to Niels Bohr, April, 30 1923, Niels Bohr Archive, Copenhagen, Denmark, Bohr Scientific Correspondence, Folder 60, Item 9: Charles Galton Darwin (1923)

C.G. Darwin, A Quantum Theory of Optical Dispersion, Proc. Natl. Acad. Sci. USA 9, 25-30 (1923)

C.G. Darwin, The Wave Theory and the Quantum Theory, Nature 111, 771-773 (1923)

C.G. Darwin, The Wave Equation of the Electron, Proc. R. Soc. A118, 654-680 (1928)

C.G. Darwin, The New Conceptions of Matter, Bell and Sons, Ltd., London (1931)

C. Davisson, Dispersion of Hydrogen and Helium on Bohr's Theory, Phys. Rev. 8, 20-27 (1916)

P. Debye, Zerstreuung von Röntgenstrahlen, Ann. Phys. 351, 809-823 (1915)

M. Dresden, H.A. Kramers: Between Tkradition and Revolution, Springer, New York (1987)

A. Duncan, M. Janssen, On the Verge of, Umdeutung in Minnesota: Van Vleck and the Correspondence Principle. Part One, Arch. Hist. Exact Sci. 61, 553-624 (2007)

A. Duncan, M. Janssen, On the Verge of Umdeutung in Minnesota: Van Vleck and the Correspondence Principle. Part Two, Arch. Hist. Exact Sci. 61, 625-671 (2007)

A. Einstein, Strahlungs-Emission und-Absorption nach der Quantentheorie, Verh. D. Phys. G. 13/14, 318-323 (1916)

F. Exner, Über Gesetze in Naturwissenschaft und Humanistik: Inaugural Address held on 15. Oct. 1908, A. Hölder, Vienna (1909) 
F. Exner, Vorlesungen Über die physikalischen Grundlagen der Naturwissenschaften, F. Deuticke, Vienna (1919)

D. Fick, H. Kant, Walther Bothe's Contributions to the Understanding of the Wave-Particle Duality of Light, Stud. Hist. Phil. Mod. Phys. 40, 395-405 (2009)

P. Forman, Landé and the Anomalous Zeeman Effect, 1919-1921, Hist. Stud. Phys. Sci. 2, 153-261 (1970)

P. Forman, Weimar Culture, Causality, and Quantum Theory, 1918-192\%: Adaption by German Physicists and Mathematicians to a Hostile Intellectual Environment, Hist. Stud. Phys. Sci. 3, 1-115 (1971)

R.H. Fowler, Letter to Niels Bohr, January 14, 1925, Niels Bohr Archive, Copenhagen, Denmark, Bohr Scientific Correspondence, Folder 92, Item 4: Ralph Howard Fowler (1925)

W. Hanle, Über den Zeemaneffekt bei der Resonanzfluoreszenz, Die Naturwissenschaften 11, 690-691 (1923)

W. Heisenberg, Zur Quantentheorie der Multiplettstruktur und der anomalen Zeemaneffekte, Z. Phys. 32, 841-860 (1925)

W. Heisenberg, Über eine Anwendung des Korrespondenzprinzips auf die Frage nach der Polarisation des Fluoreszenzlichtes, Z. Phys. 31, 617-626 (1925)

J. Hendry, The Development of Attitudes to the Wave-Particle Duality of Light and Quantum Theory, 1900-1920, Ann. Sci. 37, 59-79 (1980)

J. Hendry, Weimar Culture and Quantum Causality, Hist. Sci. 18, 155-180 (1980)

J. Hendry, Bohr-Kramers-Slater: A Virtual Theory of Virtual Oscillators and Its Role in the History of Quantum Mechanics, Centaurus 25, 189-221 (1981)

J. Hendry, The Creation of Quantum Mechanics and the Bohr-Pauli Dialogue, D. Reidel Publishing Company, Dordrecht (1984)

M. Jammer, The Conceptual Development of Quantum Mechanics, McGraw-Hill, New York (1966)

M.J. Klein, The First Phase of the Bohr-Einstein Diologue, Hist. Stud. Phys. Sci. 2, 1-39 (1970)

H. Kragh, Niels Bohr and the quantum atom : the Bohr model of atomic structure 1913 1925, Oxford University Press, Oxford (2012)

H.A. Kramers, Intensities of spectral lines: On the application of the quantum theory to the problem of the relative intensities of the components o the fine structure and of the Stark effect of these lines of the hydrogen spectrum, Det Kongelige Danske Videnskabernes Selskab. Skrifter. Naturvidenskabelig og Matematisk Afdeling 8, 285-386 (1919)

H.A. Kramers, The Law of Dispersion and Bohr's Theory of Spectra, Nature 113, 673-674 (1924)

H.A. Kramers, The Quantum Theory of Dispersion, Nature 114, 310-311 (1924)

R. Ladenburg, Die quantentheoretische Deutung der Zahl der Dispersionselektronen, Z. Phys. 4, 451-488 (1921)

R. Ladenburg, F. Reiche, Absorption, Zerstreuung und Dispersion in der Bohrschen Atomtheorie, Die Naturwissenschaften 27, 584-598 (1923)

E. MacKinnon, Models, and the Rise of Matrix Mechanics, Hist. Stud. Phys. Sci. 8, 137-188 (1977)

J. Mehra, H. Rechenberg, The Historical Development of Quantum Theory Vol. 1, Part 1: The Quantum Theory of Planck, Einstein, Bohr and Sommerfeld: Its Foundations and the Rise of Its Difficulties, 1900-1925, Springer-Verlag, New York (1982)

J. Mehra, H. Rechenberg, The Historical Development of Quantum Theory Vol. 1, Part 2: The Quantum Theory of Planck, Einstein, Bohr and Sommerfeld: Its Foundations and the Rise of Its Difficulties, 1900-1925, Springer-Verlag, New York (1982)

J. Mehra, H. Rechenberg, The Historical Development of Quantum Theory Vol. 2: The Discovery of Quantum Mechanics, 1925, Springer-Verlag, New York (1982)

R.A. Millikan, A Direct Photoelectric Determination of Planck's " $h$ ", Phys. Rev. 7, 355-388 (1916)

H.G.J. Moseley, C.G. Darwin, The Reflexion of the X-rays, Phil. Mag. 26, 210-232 (1913)

J. Navarro, "A dedicated missionary". Charles Galton Darwin and the new quantum mechanics in Britain, Stud. Hist. Phil. Mod. Phys. 40, 316-326 (2009) 
H. Poincaré, La Science et l'Hypothèse, Ernest Flammarion, Paris (1902)

H. Poincaré, Science and Hypothesis, The Walter Scott Publishing Co., Ltd., New York (1905)

H. Poincaré, Sur la théorie des quanta, J Phys. Théor. App. 2, 5-34 (1912)

E. Schrödinger, Inaugural Address before the Prussian Academy of Sciences, Die Naturwissenschaften 17, 732-733 (1929)

D. Serwer, Unmechanischer Zwang: Pauli, Heisenberg, and the Rejection of the Mechanical Atom, 1923-1925, Hist. Stud. Phys. Sci. 8, 189-256 (1977)

J.C. Slater, Radiation and Atoms, Nature 113, 307-308 (1924)

J.C. Slater, The Nature of Radiation, Nature 116, 278 (1925)

J.C. Slater, A Quantum Theory of Optical Phenomena, Phys. Rev. 25, 395-428 (1925)

J.C. Slater, Interview of John Clarke Slater by Thomas S. Kuhn and John H. Van Vleck on 1963 October 3, Niels Bohr Library \& Archives, American Institute of Physics, College Park, MD USA (1963)

J.C. Slater, Solid-State and Molecular Theory: A Scientific Biography, Wiley, New York (1975)

A. Smekal, Versuch einer allgemeinen, einheitlichen Anwendung der Quantentheorie und einer Quantentheorie der Dispersion, Die Naturwissenschaften 11, 411-412 (1923)

A. Smekal, Zur Quantentheorie der Dispersion, Die Naturwissenschaften 11, 873-875 (1923)

A. Sommerfeld, Die Drudesche Dispersionstheorie vom Standpunkte des Borschen Modelles und die Konstitution von $\mathrm{H}_{2}, \mathrm{O}_{2}$ und $\mathrm{N}_{2}$, Ann. Phys. 4, 497-550 (1917)

J. Stark, Zur experimentellen Entscheidung zwischen Aetherwellen- und Lichtquantenhypothese. I. Röntgenstrahlen, Phys. Z. 10, 902-913 (1909)

J. Stark, Über Röntgenstrahlen und die atomistische Konstitution der Strahlung, Phys. Z. 10, 579-586 (1909)

K. Stolzenburg, Niels Bohr, Collected Works Vol. 5, North-Holland, Amsterdam (1984)

R.H. Stuewer, The Compton Effect: Turning Point in Physics, Science History Publications, New York (1975)

R.H. Stuewer, The Experimental Challenge of Light Quanta, in M. Janssen, C. Lehner, eds., The Cambridge Companion to Einstein, Cambridge University Press, Cambridge (2014)

M. Stöltzner, Vienna Indeterminism: Mach, Boltzmann, Exner, Synthese 119, 85-111 (1999)

J.M. Sánchez-Ron, Charles Galton Darwin and the Nonconservation of Energy, Beni culturali scientifici nella storia e didattica. Università degli studi di Pavia 185-198 (1993)

M.J. Taltavull, Transformation of Optical Knowledge from 1870 to 1925: Optical Dispersion between Classical and Quantum Physics, Ph.D. thesis Humboldt Universität zu Berlin (2017)

G.P. Thomson, Charles Galton Darwin, 1887-1962, Bio. Memoirs Fellows R. Soc. 9, 69-85 (1963)

J.H.V. Vleck, The Absorption of Radiation by Multiply Periodic Orbits, and its Relation to the Correspondence Principle and the Rayleigh-Jeans Law. Part I. Some Extensions of the Correspondence Principle, Phys. Rev. 24, 330-346 (1924)

J.H.V. Vleck, The Absorption of Radiation by Multiply Periodic Orbits, and its Relation to the Correspondence Principle and the Rayleigh-Jeans Law. Part II. Calculation of absorption by Multiply Periodic Orbits, Phys. Rev. 24, 347-365 (1924)

D.L. Webster, Quantum Emission Phenomena in Radiation, Phys. Rev. 16, 31-40 (1920)

D.L. Webster, Interview of David Webster by W. James King on 1964 May 21, Niels Bohr Library \& Archives, American Institute of Physics, College Park, MD USA (1964)

C.T.R. Wilson, Investigations on X-Rays and $\beta$-Rays by the Cloud Method. Part 1 - X-Rays, Proc. R. Soc. A104, 1-24 (1923)

R. Wood, Selective Reflexion of $\lambda 2536$ by Mercury Vapour, Phil. Mag. 44, 1105-1106 (1922)

R. Wood, A. Ellett, On the Influence of Magnetic Fields on the Polarisation of Resonance Radiation, Proc. R. Soc. 103, 396-403 (1923) 